九州大学学術情報リポジトリ

Kyushu University Institutional Repository

\title{
On The Chemical Constituents of The Heart Wood Of Distylium Racemosum S. ET Z. (First Report)
}

Kondo, Tamio

Department of Agriculture, Kyusyu University

https://doi.org/10.5109/22646

出版情報: 九州大学大学院農学研究院紀要. 10 (1)，pp.79-99，1951-10. Kyushu University バージョン：

権利関係 : 
Journal of the Faculty of Agriculture, Kyūshū University, Vol. 10, No. 1

October 30, 1951

\section{ON THE CHEMICAL CONSTITUENTS OF THE HEART WOOD OF DISTYLIUM RACEMOSUM S. ET Z.}

(First Report)

TAMIO KONDO

\section{INTRODUCTION}

The discrimination of wood specimen is usually made by means of the difference of the constitutions of wood tissue, in other words, it is made from anatomical view points, but a few chemical methods, such as Mäule reaction, ${ }^{1)}$ fluorescence reaction ${ }^{2)}$ and flavone reaction, have been used as auxiliary means. Among these chemical methods, we prefer so called flavone reaction to others for the reason that this method has distinctive advantages such as that there are only a limited number of wood specimen which show positive reaction, ${ }^{3)}$ that its operation is simple and that its reaction can be observed with the naked eye.

The technical process of the method is as follows: :) $^{\text {) }}$

The subject wood is sawed into fine dust and the dust is immersed in alcohol or methanol overnight from which alcoholic extract is separated. When a small volume of metallic magnesium or a few drops of mineralic acid is added to the extract with a few drops of mercury (or without it), it presents instantly reddish coloration. As the mineralic acid agent, we usually use sulphuric acid and hydrochloric acid, but sometimes organic acid such as acetic acid is found sufficient for the purpose.

Its tinct of coloration is usually reddish, but sometimes we observe only yellowish coloration. For example, in the case of alpinon which exists in "Semen Alpiniae" which does not possess free hydroxyl group in the side phenyl radical, it presents a yellowish coloration only. ${ }^{5}$ ) 
The chemical process of the flavone reaction is accounted for as follows: So called flavone substance in wood tissue is discharged into organic solvent. When it is reduced severely by hydrogen gas in the nascent state under the influence of mineralic acid, it is converted into so called anthocyan series which presents a distinct coloration.

The substances which react positively on flavone reaction are limited to such series as flavone, flavonol (3-oxy-flavone), flavanone (2, 3,-dihydro-flavone), flavanonol (2-hydro-3-oxy flavone,) and a few xanthione derivatives. ${ }^{8}$. Therefore it was proposed that the term "magnesium-hydrochloric acid reaction" is more suitable than so called "flavone reaction" in the original sense of the word.

In the past, many studies on plant pigment have been mainly directed on its exterior tissues: such as flowers, leaves, roots and barks; and in addition, these studies have been originated from the interest of medicine and dyestuffs. Accordingly very little has been studied from the botanical standpoint for the classification of plant species, particularly of wood specimen.

However, recently an opinion was expressed that not only morphological characteristics of a plant but its constitutional features must be equally taken into consideration for the classification of plant species, so the idea of species should be considered from the standpoint of both morphological and physiological aspects. ${ }^{8)}$

Such an idea was first expressed by Friedrich Boas in his work "Dynamische Botanik", where he termed it "das Souderstoff". ${ }^{\text {) }}$

On the other hand, Dr. Asahina and his co-workers have studied chemically and botanically moss materials in details, and utilized a special colouring reaction in the classification of its variety..$^{10)}$

In wood chemistry, the genus Aesculus is - likely to contain aesculetin add all species of the genus Fraxinus to contain homologue fraxetin. ${ }^{11}$

Of course it is unreasonable to attempt the classification of plant-species basing only on their constitutional materials.

In the past, many of the chemical studies on wood have been carried towards the direction of the general chemical analysis. 
It is worthy of closer attention that Erdmann and Nozoe recently discovered respectively thujaplicin (three $\alpha, \beta, \gamma$-homologues) and hinokitiol, from woods of Thuja plicata Dovand and Chamaecyparis taiwanensis Masamune et Suzuki in their own way. Both of them belong to a type of keto-enolic cycloheptatrieneolone (tropolone series) which possess an antibacterial effect against wood decaying fungi..$^{12,13)}$

Literature of chemical studies on wood constituents is very scarce. $^{14,15,18)}$

Now the term "flavone pigment" in this essay means the plant pigments which will be called "flavone" in a broad sense, containing flavonol, flavanone, flavanonol homologues.

On the other hand a view on the plant physiological significance of flavone pigment by Shibata ${ }^{17}$ ) has been generally admitted. To summarize his theory: these pigments, which dissolve in cell sap, absorb the ultraviolet rays of the sun light and accordingly protect protoplasma from a toxic action of these rays. In this sense the pigments are cell shelter against the ultraviolet rays. As the experimental foundations of this theory, it is emphasized as follows; first of all, these pigments are found universally in many higher plants, furthermore even in the same plant its content is more abundant in the exterior tissues than in the inner organs. The pigment-content in plant is known to increase according to the elevation of planted site in altitude. In addition, the recent spectroscopic studies have shown us the fact that these pigments strongly absorb the ultraviolet rays. However, recently the development of physical organic chemistry has revealed the facts that various natural organic substances show the absorption spectrum to the ultraviolet rays or infrared rays. Furthermore these pigments have been also detected in the underground organs, such as roots, hulls and even in heart wood of trees which are not directly affected by sun light. ${ }^{17,19}{ }^{19}$ ) Accordingly it is presumed as probable that these plant pigments would have much broader physiological bearing upon plant, organs.

As to the physiological mechanism of the pigment formation in plant organ, now we are nearly ignorant on this subject as well as on the other materials. But from some simple consideration it has been assumed that flavone pigment is a forerunner of anthocyan pigment. ${ }^{20)}$ 
When we turn our eyes to pharmacological effect of plant pigment, first of all we shall become aware of anthrachinone homologues which is recognized as a laxative and a urinating agent, ${ }^{21,22)}$ such as emodine and chrysophanic acid from Rhizoma Rhei, root of Rheum palnatum L. var tanguticum Maxim. Furthermore we shall notice a literature that flavone and its glucosides have also urinating effect. ${ }^{23}$ ) Recently it was reported that pure ascorbic acid alone will have clinically no effect on a kind of blooding disease, but it will have an excellent effect on the patient when the dose is supplementarily with Vitamin P. ${ }^{24}$ ) This V.P. (or citrin) was lately decided as a mixed crystal of a flavanone glucoside, hesperidin, and a free flavanone, eriodictyol..$^{25}$ A few years ago some interesting studies on rutin, which is a quercetin3-rhamnoglucoside obtained from tobacco leaves, etc., were published in an American Technical Journal. ${ }^{28)}$ From the results of its clinical experiment it was recognized that this pigment has an excellent regulating action against the permeability of human blood vessels, namely to high blood-pressure disease and internal haemorrhage. And we know another physiological effect of rutin. ${ }^{27)}$ In America this pigment is now extracted from whole buckwheat glass and sold as rutin-tablet. Now in the field of medicine, the utilization of flavone pigment has been also closed up to our attention.

In the following scheme we can see the close chemical and physiological relationship between flavone pigments and anthocyane pigments or catechine series, which is one of the so called tannin substances.

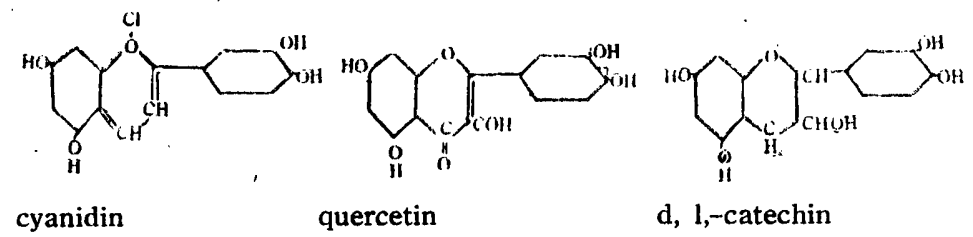

Three substances mentioned above are structurally in oxidation and reduction type to each other. Really a flavone pigment, such as apigenine was reduced with sodium amalgam, acidified on addition of hydrochloric acid, and so the acquired precipitate was dissolved in alcohol, then added with ether, and the substance obtained in red needles was recognized as cyanidine. ${ }^{28)}$ 
From the fact that both of these pigments are found in the same plant and also catechin is contained together with a corresponding flavonol, ${ }^{20}$ ) there has been a proposal that it would strongly point to a physiological relationship among those substances, ${ }^{30)}$ but naturally these conclusions are doubtfull. However in a chemical laboratory reduction of flavonol into dl-catechin is attainable, ${ }^{31}$ ) and the anthocyan series is converted into catechin through direct reduction. ${ }^{32}$

As given above the so called flavone pigment contains four distinct types with regard to chemical structure.

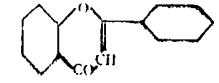

flavon type

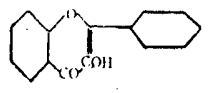

flavonol type

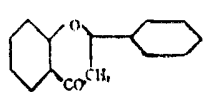

flavanon type

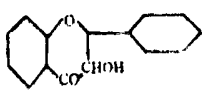

flavanonol type

All substances which belong to the four types are positive to the magnesium hydrochloric acid-reaction, giving bulky precipitates with lead acetate solution, and commonly breaking an oxygen bridge of $r$-pyron through the introduction of caustic solution. The first three types had been found in plant organ since old times, but the last flavononol series, was lately discovered. Fustin from the heart wood of Rhus succendanea L. by T. Oyamada, ${ }^{33}$ alpinon from the Semen Alpiniae, seed of Alpinia japonica Mig. by Y. Kimura, ${ }^{34)}$ ampeloptin from Ampelopsis neliafolia Kudo by T. Kubota, ${ }^{35}$ and katuranin from Cercidiphyllum japonicum $S$. et $Z$. by $\mathrm{H}$. Uota, T. Fukushima and T. Kondo") are all that belong to this type of substances which we are able to find in the literature hitherto published.

Dr. Nishida has maintained an opinion that on sulphite pulping the flavone pigment contained in the original wood will cause more or less pitch trouble, and recently a few studies were made from such a point of view. ${ }^{39}$ In fact, Larix Kaempferi Sorg., Cercidiphyllum japonica S. et Z., Distylium racemosum S. et $Z$. are known as the most difficult woods on sulphite pulping, and contain a good amount of flavone pigment in each.

It should be noticed that such woods contain more or less flavone pigment which has such various significances as above mentioned.

Here the author attempted to identify chemically those positive substances to magnesium hydrochloric acid reaction in Distylium 
racemosum $S$. et $Z$.

As chemical studies on Distylium racemosum $S$. et $Z$. we know only a few general analysis of wood ${ }^{37,38,39)}$ and ash-analysis, ${ }^{40)}$ for its ash has been utilized for a glazing mixture of "Arita ware".

In the test tube the author found that a sap wood contains scarcely such positive substances, so only heart wood was selected as material. This heart wood was sawed into powder, dried in the air. At first the author employed the usual lead acetate method as isolation process, ${ }^{41)}$ but his result was unsuccessful. The heart wood contained a great amount of tannin substance which possesses a similar constitution to flavone pigment and this catechol tannin would cause the isolation hinderance. Later he extracted pigments successfully from the saw dust with absolute ether in which tannin substance is insoluble. And two pigments were obtained from the ether extract, the one was recognized as quercetin that was first detected in the bark of Quercus discolor Ait. ${ }^{22}$ and later isolated from many other plants. The other was here identified as 2-3-dihydroquercetin.

During and after the second world war we have been shut out from foreign literature, moreover even the domestic chemical publications are difficult to obtain. So the author will name provisionally the latter pigment .as "Distylin" after its original plant name.

However recently the author obtained some American chemical literature, and among this found John Pew's study on "Douglas Fir Flavanone". ${ }^{43)}$ His so-called "Douglas Fir Flavanone" is identical with an optical isomer of the author's preparation, Distylin, according to his following experimental description. In addition, the author has come to be aware of shkimetin, which M. Takasaka and his co-worker isolated from a bark of Illicium religiosum $\mathrm{S}$. et $Z^{44}{ }^{44}$ Shkimetin has an identical construction $\mathrm{C}_{15} \mathrm{H}_{12} \mathrm{O}_{7}$ and assumed as quercetin-dihydro compound. But they described only one derivative, acetylshkimetin $\mathrm{C}_{25} \mathrm{H}_{22} \mathrm{O}_{12} \mathrm{mp} .152 .5^{\circ}$ and no optical reference, nor further investigation in details was reported. 


\section{CHAPTER I \\ Isolation of Two Pigments}

In plant chemistry we usually use the lead-acetate method as isolation process of plant constituents. ${ }^{41)}$ Especially has this method been favourably employed for the isolation of pigments, tannin substances, some kinds of glucosides and a few polyphenols. It is based on the following principle; these plant constituents, which show more or less acidic tendency in aqueous or alcoholic solution, react with lead acetate into its lead salts or an additionproduct which is insoluble in water or organic solvents. These insoluble products are separated from some impurities, decomposed by dilute sulphuric acid or hydrogen sulfide into a free state.

Formerly the author extracted a new pigment from Cercidiphyllum japonicum $\mathrm{S}$. et $Z$. with this method under the guidance of former Assistant Professor $H$. Uota. ${ }^{7)}$ In the preliminary experiment the author found that this isolation method was not successful on the above mentioned material. The heart wood of Distylium racemosum $S$. et $Z$. had a large quantity of tannin substance, which is likely to belong to a catechol group judging from a few coloring reactions. It may be easily imagined that its similar chemical construction to the pigments seems to cause the difficulty in isolating them from each other.

Distylium racemosum S. et $Z$. is a tall ever-green tree, belonging to the Hamamelidaceae family, which grows natively in the southern districts of Japan, Kyushu, Shikoku and Tsushima. Especially southern Kyushu has this abundant wood reserve. In April it blossoms and the fruiting season in October. This wood is very hard, since it is one of the heaviest woods in Japan. It is utilized as a material for house-building, utensils, furnitures, musical instruments, comb-manufacturing. Ash of the whole wood has been also used as a component of the glazing mixture of "Arita ware". Still more interesting to note is that in the mountainous region of Kyushu it is a popular thing to make a mimic sword from this wood and then season it in a paddy field for a few months. Through this treatment the sword surface becomes purplish black and the lusture is enhanced brilliantly. As a reason for the development of this coloration it may be properly con- 
sidered that tannin substance, which is richly contained in the wood material, reacts with the ferric salt in a paddy field.

In consideration of the result of the preliminary experiment, the author extracted successfully with absolute ether, in which tannin substance is nearly insoluble. From the ether extract two crystals were obtained. Both crystals were positive to the magnesium hydrochloric acid reaction, one was a lemon-like yellow needle and the other a colourless crystal. The latter was provisionally named "Distylin" by the author.

In the literature we find a few researches on such pigments from the plant material. T. Oyamada isolated a yellow needle, fisetin $\mathrm{C}_{15} \mathrm{H}_{10} \mathrm{O}_{8}$ and a colourless crystal, fustin $\mathrm{C}_{15} \mathrm{H}_{12} \mathrm{O}_{n}$ from the heart wood of Rhus succedanea L ${ }^{33)}$ Myricetin, yellow needle $\mathrm{C}_{15} \mathrm{H}_{10} \mathrm{O}_{\mathrm{s}}$ and ampeloptin, colourless crystal $\mathrm{C}_{15} \mathrm{H}_{12} \mathrm{O}_{8}$, were isolated from Ampelopsis melisefolia Kudo by $\mathrm{H}$. Kubota through the usual lead-acetate method ${ }^{36)}$ These experiments suggested that there is such similar relationship between both crystals obtained each by the author.

\section{Experimental}

The plant used in this experiment was contributed through the courtesy of the Tsuma Forestry Office, Kumamoto Forestry Bureau. The plant was used about one year after felling. Through cutting off sap wood only heart wood was collected. The heart wood was sawed into pieces and this saw dust dried in the air. The ground material was extracted in a continuous extractor with absolute ether for 7-10 days. Yellowish ether extract was evaporated on the water bath, and yielded a brown crystal mass containing some oily crust.

For removing the oily substance the crystal mass was extracted in Soxhlets with benzene until benzene extract becames colourless. The benzene insoluble mass was treated with hot water, divided into two fractions.

The one, insoluble part in hot water, afforded a brownish yellow mass. After several times of recrystallization from alcohol with charcoal, it gave fine yellow needles, m.p. $307-310^{\circ} \mathrm{C}$ under decomposition.

The other, in hot water soluble part, was allowed to cool to room temperature and gave fine leaflet crystals which sometimes 
crystallized in needles. The colourless crystal was filtered, washed with cold water, and pressed on a porous plate. On recrystallization from hot water or dilute alcohol it became fine shiny leaflet crystal, m.p. $228-229^{\circ} \mathrm{C}$ under brownish decomposition. The yield of the yellow crystals was $0.7 \%$ to the weight of the original wood-powder and that of the colourless crystal was about $2.3 \%$.

\section{Chapter II \\ Identification of Quercetin}

The hot water insoluble crystal is fine lemon-coloured needle and shows itself one of positive substances to the magnesium hydrochloric acid reaction in the wood material by its positive red coloration. It melts at the interval of $307-310^{\circ} \mathrm{C}$ with blackish decomposition, but the melting point is raised to about $315^{\circ} \mathrm{C}$ through acute heating.

From the results of its elemental analysis the molecular formula of the crystal is found in agreement with $\mathrm{C}_{15} \mathrm{H}_{10} \mathrm{O}_{7}$. In addition some chemical behaviours suggest it to be quercetin, in the literature. To confirm this assumption the present author prepared a few derivatives as follows.

On the treatment with acetic anhydride and a drop of conc. sulphuric acid it gave a colourless needle, m.p. $197.5^{\circ} \mathrm{C}$. This needle was identified with pentaacetyl-quercetin from the analytical figures and the mixed melting point determination with known one. Furthermore the author attempted the preparation of its methyl derivatives and when dealt with methyliodide and anhydrous potassium carbonate in acetone solution, a light yellow long needle was obtained. Through the same procedure it was decided to be tetramethyl-quercetin. The tetramethylquercetin has m.p. $155^{\circ} \mathrm{C}$ and is soluble in alkali. Its alcoholic solution shows positive reaction to ferric chloride solution. So the substance has more free phenolic hydroxyl groups.

It has been established in the literature that the free hydroxyl which is located in the para-position to the carbonyl radical is more resistently. alkylized. ${ }^{45}$ With regard to quercetin it will be properly proposed that it has the chelation structure which is to be expressed according to the following scheme. ${ }^{46}$ 


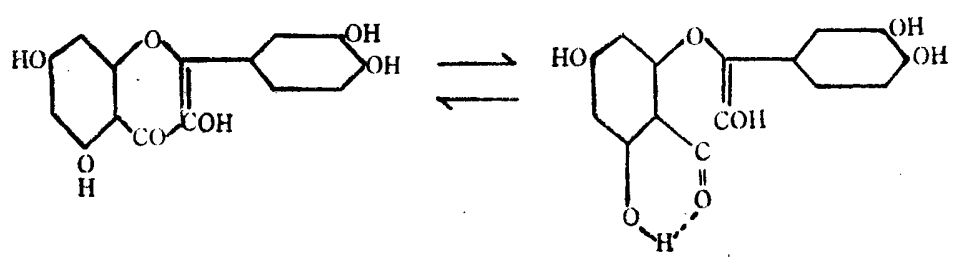

Such chelate ring may be more stable owing to hexacyclic formation, so it becomes more difficult to substitute the $\mathrm{C}_{5}$ hydrogen atom by the alkyl group. The author used dimethyl sulphate as an alkylating agent.

In the literature $\gamma$-pyron ring in benzopyron molecule can be easily opened by alkali reagents. ${ }^{47}$ ) So during the alkylating operation an excess of alkali should be strictly avoided. It was first successful when the same operation with dimethylsulphate and soda had been repeated three times under close observation.

The reaction product is a colourless prism, m.p. $148^{\circ} \mathrm{C}$, insoluble in alkali, gives no coloration with ferric chloride solution and also sensitively melts at $112^{\circ} \mathrm{C}$ when recrystallized from dilute methyl alcohol. With the elemental figures it is recognized as pentamethylquercetin. ${ }^{48}$ ) In the past, quercetin and its glycosides have been detected in many plants, but aside from the study on Larix Kaempferi Sorg. ${ }^{49}$ we could not find any study of quercetin from wood materials.

\section{Experimental}

The lemon-coloured crystal is easily soluble in acetone, ether, hot alcohol, and pyridine, and is nearly insoluble in water, benzene and chloroform. Its alkali solution presents yellow coloration and gradually becomes brownish on standing. The alcoholic solution gives blackish green coloration with ferric chloride and also gives deep red coloration when reduced with metallic magnesium and conc. hydrochloric acid, with lead acetate solution it yields bulky red precipitate and strongly reduces Fehling's solution.

Anal. Sample was dried at the boiling point of toluene in Vacuum.

$\begin{array}{lccccc} & \text { Subst. } & \mathrm{CO}_{2} & \mathrm{H}_{2} \mathrm{O} & \mathrm{C} \% & \mathrm{H} \% \\ \text { Found } \quad 16.7 \mathrm{mg} & 36.60 \mathrm{mg} & 5.50 \mathrm{mg} & 59.81 & 3.65 \\ \text { Calc. for } \mathrm{C}_{15} \mathrm{H}_{10} \mathrm{O}_{7} & & & 59.60 & 3.31\end{array}$

Acetyl-derivative; 
The pigment was suspended in acetic anhydride and then was added to it a drop of sulphuric acid, it was dissolved into a reddish light yellow solution. Under stirring the reaction product was poured in to a great amount of cold water. With decomposition of acetic anhydride it changed to white mass, which after filteration was washed with water until no odour of acetic acid remained. On recrystallization from $95 \%$ alcohol it afforded fine colourless needles, m.p. $197.5^{\circ} \mathrm{C}$. It showed no depression on the mixed melting point determination with known pentaacetylquercetin. The crystal was not soluble in alkali and gave no coloration with ferric chloride.

Anal. Sample was treated as above described.

$\begin{array}{lccccc} & \text { Subst. } & \mathrm{CO}_{2} & \mathrm{H}_{2} \mathrm{O} & \mathrm{C} \% & \mathrm{H} \% \\ \text { Found } & 16.8 \mathrm{mg} & 36.0 \mathrm{mg} & 6.0 \mathrm{mg} & 58.48 & 3.96 \\ \text { Calc. for } \mathrm{C}_{15} \mathrm{H}_{5} \mathrm{O}_{7}\left(\mathrm{COCH}_{3}\right)_{5} & & & & 58.59 & 3.96\end{array}$

Methyl derivatives:

1) Methylation with methyliodide and $\mathrm{K}_{2} \mathrm{CO}_{3}$

A little excess of methyliodide and anhydrous postassium carbonate was added to acetone solution of the pigment, refluxed on water bath for a few hours and filtered from the potassium salt. The acetone solution was evaporated to dryness and so the obtained crystal mass was recrystallized from methanol with active carbon. The methyl derivative was a light yellowish long needle, m.p. $155^{\circ} \mathrm{C}$, soluble in alkali and gave a positive reaction to ferric chloride solution. No depression on the mixed melting point examination with know tetramethyl quercetin m.p. $156^{\circ} \mathrm{C}$.

\begin{tabular}{|c|c|c|c|c|}
\hline & Subst. & $\mathrm{CO}_{2}$ & $\mathrm{H}_{2} \mathrm{O}$ & $\mathrm{C} \%$ \\
\hline Found & $18.9 \mathrm{mg}$ & $44.0 \mathrm{mg}$ & $8.9 \mathrm{mg}$ & 63.53 \\
\hline \multicolumn{4}{|c|}{ Calc. for $\mathrm{C}_{15} \mathrm{H}_{6} \mathrm{O}_{7}\left(\mathrm{CH}_{3}\right)_{4}$} & 63.68 \\
\hline
\end{tabular}

\section{2) Methylation with dimethylsulphate and $\mathrm{NaOH}$}

In methanolic solution of the pigment two times as much dimethyl sulphate was mixed, in which $10 \%$ soda solution was added drop by drop under severe stirring and careful precaution against its strong alkali reaction. After this procedure the product was still positive to the ferric chloride reaction. So this treatment was repeated three times on each product, and finally there was obtained a crystal indifferent to the ferric chloride reaction. Its 
methanolic solution gave a light red tint on treating with metallic magnesium and conc. hydrochloric acid. When recrystallized from dilute methanolic solution. it melted at $112^{\circ} \mathrm{C}$. Those qualities of the crystal were correspondent with one of pentamethyl-quercetin in the literature. $\left.{ }^{43}\right)$

\begin{tabular}{lccccc} 
Anal. Sample (vacuum const.) & & & \\
\multicolumn{7}{c}{ Subst. } & $\mathrm{CO}_{2}$ & $\mathrm{H}_{2} \mathrm{O}$ & $\mathrm{C} \%$ & $\mathrm{H} \%$ \\
Found & $17.1 \mathrm{mg}$ & $40.1 \mathrm{mg}$ & $8.5 \mathrm{mg}$ & 64.00 & 5.52 \\
Calc. for $\mathrm{C}_{15} \mathrm{H}_{5} \mathrm{O}_{7}\left(\mathrm{CH}_{3}\right)_{5}$ & & & 64.54 & 5.37
\end{tabular}

\section{ChAPTER III}

Physical and Chemical Properties of the Colourless Crystal

The colourless crystal obtained from the heart wood of Distylium racemosum $S$. et $Z$. formed itself into needles or plates depending on the conditions of recrystallization from water. However, when only needles were collected and recrystallized by the use of hot water they were occasionally obtained in plates. Kubota observed such dimorphism in the pigment of the homologous series, ampeloptin. ${ }^{35)}$ Generally there has been observed polymorphism on many inorganic compounds, but rarely on few organic substances, such as cumarin ${ }^{50}$ and barbital. ${ }^{51)}$ Among natural organic compounds gallic acid, ${ }^{52}$ chrysophanic $\operatorname{acid}^{53)}$ and morphine ${ }^{\text {s4) }}$ were reported.

On heating in capillary tube it develops a light coloration at about $200^{\circ} \mathrm{C}$, and becomes gradually deeper in tint and melts at $228-229^{\circ} \mathrm{C}$ under decomposition. As to the decomposition point the author observed some ranges depended on the rate of heating. It is raised to about $400^{\circ} \mathrm{C}$ by acute heating.

To confirm the purity of the crystal, acetylderivative, m.p. $153^{\circ} \mathrm{C}$ was prepared by the method which will be described in the next chapter and hydrolyzed with alcoholic sulphuric acid. The product was recrystallized from water in the same crystalline form as the original substance and melted at $228-220^{\circ} \mathrm{C}$. However saponification with alcoholic kali was unsuccessful, because pyronring was broken by alkali reagents. So the crystal, m.p. $228-229^{\circ} \mathrm{C}$ is properly determined as a pure one for the following experiments. In the introduction the author named this crystal distylin. 
It is soluble in hot water, methanol, alcohol, acetone and pyridine, insoluble in benzene, toluene, chloroform and cold water. It dissolves in bicarbonate solution, but no bubbling of carbon dioxide is seen. Its alkali solution is light yellow at first, and gradually becomes reddish violet. In conc. sulphuric acid it dissolves fresh yellow, but becomes colourless when a large quantity of water is added to it.

So the crystal develops a faint halochromy which may be considered as the characteristic colour reaction of unsaturated ketones. It gives the same colour reaction on addition of conc. sulphuric acid to the glacial acetic acid solution of the colourless pigment, but does not precipitate its oxoniumsalt. The aqueous solution gives a green coloration with ferric chloride solution, which becomes gradually blackish green. This green solution turns instantly into reddish violet when a drop of soda solution is added. Through this discoloration the crystalline substance suggested as a orthodiphenyl compound. ${ }^{\text {B5 }}$. In the alcoholic solution it raises a blackish violet coloration with the ferric chloride solution and a light reddish with the metallic magnesium and conc. hydrochloric acid. But this coloration is also developed with granulated zinc and conc. hydrochloric acid, which has been lately reported as the characteristic of 3, 4 -dihydroflavonol compounds. ${ }^{43}$ Lead acetate solution gives voluminous dirty yellow precipitates. It reduces ammoniacal silver nitrate solution and Fehling's solution. The specific rotatory power was examinned in acetone solution and alcoholic solution, but it was inactive in both solutions.

Through the above qualitative reactions the product was suggested as a substance of flavone series. Generally flavone pigments in plants were detected in forms of a free state or of glucoside. So the present author attempted to hydrolyse with mineral acid. The long action of dilute sulphuric acid to the product converted it in a yellowish crystal which was decided to be quercetin through the mixed melting point determination of its acetate with known pentaacetyl quercetin. The filtrate strongly reduces Fehling's solution after neutralization with potash. However the mother liquor was repeatedly extracted with ether and all reducing materials were found only in the ether extract. The ether extract was dried with Glauber's salt, evaporated to dryness 
and the residue was divided into two fractions. The one was the unchanged original substance and the other was quercetin. So the reducing power of the mother liquor should be originated from two compounds, namely quercetin and colourless pigment. The mother liquor after ether extraction was neutralised with barium carbonate and evaporated to dryness. The residue was examined on organic compounds but no organic substance was recognized.

T. Oyamada got the corresponding dihydrocompound, fisetin, through long action of dilute mineralic acid to fustin under reduced pressure and normal pressure. So the author's colourless crystal is not glucoside but a substance which has a close structural resemblance to quercetin. The data of measurements of the molecular weight, water of crystallization and elementary analysis are in strict agreement with chemical formulation $\mathrm{C}_{18} \mathrm{H}_{12} \mathrm{O}_{7} \cdot 1 \frac{1}{2} \mathrm{H}_{2} \mathrm{O}$.

\section{Experimental}

Measurement of the molecular weight:

The molecular weight of this substance was determined by Akiya's method, ${ }^{56}$ ) which Professor Akiya modified dextrously the original Barger's method, ${ }^{57}$ ) because the pigment dissolves in camphor under yellowish decomposition. As a solvent the author selected acetone and as standard substance azobenzene (m.p. $68^{\circ} \mathrm{C}$ ) was charged.

1) Preparation of two solutions.

a) the object solution: $0.304 \mathrm{~g}$ of the product was dissolved in $5 \mathrm{cc}$ of acetone $(60.8 \mathrm{~g}$ in Liter)

b) the control solution: the standard solution of 0.3 molarity was prepared, in which $0.546 \mathrm{~g}$ of azobenzene (molecular weight 182) was dissolved in $10 \mathrm{cc}$ of acetone. This original solution was diluted as follows:

\begin{tabular}{|c|c|c|c|c|}
\hline No. & Original solution & $\begin{array}{l}\text { Acetone } \\
\text { (cc.) }\end{array}$ & Molarity & $\begin{array}{c}\text { Corresponding } \\
\text { mol. weight } \\
\text { M.W. }=\frac{60.8 \text { in } L}{\text { Mol. }}\end{array}$ \\
\hline 1 & / & $/$ & 0.30 & 203 \\
\hline 2 & 1.0 & 0.20 & 0.25 & 243 \\
\hline 3 & 1.0 & 0.50 & 0.20 & 304 \\
\hline 4 & 1.0 & 0.76 & 0.17 & 358 \\
\hline 5 & 1.0 & 1.14 & 0.14 & 434 \\
\hline
\end{tabular}


2) Measurement: author employed a sliding microscope of 100 magnifications with ocular micrometer and measured a tube length which was located in the middle portion at the water temperature $24^{\circ} \mathrm{C}$.

\begin{tabular}{|c|c|c|c|c|c|c|c|}
\hline No. ' & M.W. $\frac{\min .}{\text { length }}$ & 0 & 60 & 145 & 215 & 590 & Difference \\
\hline 1 & 203 & 8.30 & 8.15 & 7.98 & 79.8 & 7.55 & -0.75 \\
\hline 2 & 243 & 17.10 & 17.00 & 16.93 & 16.90 & 16.35 & -0.75 \\
\hline 3 & 304 & 13.39 & 13.35 & 13.38 & 13.35 & 13.35 & -0.04 \\
\hline 4 & 358 & 13.65 & 13.70 & 13.80 & 13.90 & 14.10 & +0.45 \\
\hline 5 & 434 & 15.70 & 15.80 & 15.80 & 15.80 & 16.10 & +0.40 \\
\hline
\end{tabular}

So the molecular weight was demonstrated as being between No. 3 and No. 4. Provisionally the mathematical average would be calculated as follows;

$$
\begin{aligned}
& \text { M.W. }=\frac{304+358}{2}=331 \\
& \text { calc. for } \mathrm{C}_{15} \mathrm{H}_{12} \mathrm{O}_{7} \cdot 1_{2}^{1} \mathrm{H}_{2} \mathrm{O} 331
\end{aligned}
$$

Measurement of the water of crystallization:

The substance was dried at the boiling point of toluene in high vacuum for five hours.

$\begin{array}{llccr}\text { Subst } 283.9 \mathrm{mg} & \text { Loss in weight } & 23.2 \mathrm{mg} & 8.14 \% \\ \text { " } & 137.5 \text { " } & \text { " } & 11.5 \text { " } & 8.36 \% \\ & & \text { Calc. for } \mathrm{C}_{15} \mathrm{H}_{12} \mathrm{O}_{7} \cdot \mathrm{H}_{2} \mathrm{O} & 5.60 " \\ & & \text { " } \mathrm{C}_{15} \mathrm{H}_{12} \mathrm{O}_{7} \cdot 1 \mathrm{H}_{2} \mathrm{O} & 8.30 " \\ & & \text { " } \mathrm{C}_{15} \mathrm{H}_{12} \mathrm{O}_{7} \cdot 2 \mathrm{H}_{2} \mathrm{O} & 11.10 "\end{array}$

Anal. Sample (vacuum const.)

$\begin{array}{llrrr}\text { Subst. } & \mathrm{CO}_{2} & \mathrm{H}_{2} \mathrm{O} & \mathrm{C} \% & \mathrm{H} \% \\ 20.9 \mathrm{mg} & 45.3 & 7.7 & 59.15 & 4.09 \\ 19.9 \mathrm{mg} & 43.0 & 7.3 & 58.97 & .4 .04 \\ & \text { Calc. for } \mathrm{C}_{15} \mathrm{H}_{12} \mathrm{O}_{7} & 59.21 & 3.94\end{array}$

Action of dilute sulphuric acid on colourless crystal.

$2 \mathrm{~g}$ of the substance were added in $100 \mathrm{cc}$ of $3 \%$ sulphuric acid and the mixture gradually became a reddish violet to light yellow when slightly boiled on wire gauze for several hours. After fourteen hours it yielded crystalline mass in lukewarm con. dition. The mass was filtered and weighed about $0.35 \mathrm{~g}$. The mother liquid gave an unchanged original substance, $0.6 \mathrm{~g}$, on cooling. The crystalline mass was lemon-like yellow needles, on 
recrystallization from alcohol it gave fine yellow crystals, m.p. $307^{\circ} \mathrm{C}$. The alcoholic solution was positive to the magnesium hydrochloric acid reaction and developed a greenish brown on ferric chloride solution. On usual acetylation with acetic anhydride and conc. sulphuric acid it yielded colourless needles, m.p. $196^{\circ} \mathrm{C}$. The acetate was identified as quercetin pentaacetate through the mixed melting point determination with known one.

When the mother liquid of quercetin and of the unchanged substance was treated with steam distillation the author acquired no acidic distillate. The liquid strongly reduced Fehling's solution, but the reducing substance was transferred into ether layers, on repeating extraction with ether, after saturation with common salt. The ether solution was treated with the usual method and divided into two fractions. From the acidic fraction it gave an unchanged substance and from the phenolic fraction it yielded a few querection. So the reducing activity of the mother liquid must be considered as being originated from one of quercetin and the colourless pigment, because the residual liquid of ether extraction gave no organic substance after neutralization with barium carbonate. .

\section{CHAPTER IV}

\section{Derivatives of D Distylin}

Distylin has evidently the molecular formula, $\mathrm{C}_{15} \mathrm{H}_{12} \mathrm{O}_{7}$ and belongs to the so-called flavone pigment (the carbon number of its 'standard structure $=15$ ), because it develops an apparent magnesium-hydrochloric acid reaction. With regard to the function of oxygen it is obvious that two of them are pyronring's, so the remaining five must be determined up on its function. Therefore the author attempted to prepare its alkyl- and acylderivatives. At first the acetyl derivative was prepared; distylin was suspended in acetic anhydride and a drop of conc. sulphuric acid was added to it, then the product was recrystallized from methanol. A colourless needle was obtained, m.p. $153^{\circ} \mathrm{C}$. The $\mathrm{Mg}-\mathrm{HCl}$ reaction was indistinct in its alcoholic solution, but clear in the methanolic solution. The methanolic solution was also inactive to the ferric chloride solution. It was insoluble in alkali. From the result of this elementary analysis. it is in agreement 
with pentaacetyl-distylin. The author acquired the same product through the treatment with pyridine and acetic anhydride.

Then the benzoyl derivative was prepared by the similar method with that of acetylation described above and its product was a colourless needle, m.p. $200^{\circ} \mathrm{C}$. The solution, in which the benzoyl product was dissolved in large quantity of alcohol, was positive to the $\mathrm{Mg} \cdot \mathrm{HCl}$ reaction. When the benzoyl product was once more benzoylated with pyridine and benzoychloride, but only the original substance was obtained. From the figures of elementary analysis it was confirmed that it was identical with pentaacetyldistylin $\mathrm{C}_{15} \mathrm{H}_{7} \mathrm{O}_{7}\left(\mathrm{COC}_{6} \mathrm{H}_{5}\right)_{5}$. Furthermore the author obtained tetrabenzoyl-distylin $\mathrm{C}_{15} \mathrm{H}_{8} \mathrm{O}_{7}\left(\mathrm{COC}_{8} \mathrm{H}_{5}\right)_{4}$, when benzoylation did not satisfactorily result. This product is a colourless needle and does not develop coloration to ferric chloride in its alcoholic solution. It melted at $192^{\circ} \mathrm{C}$. The same tetramethyl-distylin was prepared through the usual three methylating agents: methyliodide and potassium carbonate, dimethyl sulphate and alkali, and diazomethane. It is a colourless needle, m.p. $170^{\circ} \mathrm{C}$, inactive to ferric chloride in the methanol solution, and develops light reddish colour to the $\mathrm{Mg}-\mathrm{HCl}$ reaction. From both the elementary analysis and the measurement of the methoxyl groups it is in agreement with $\mathrm{C}_{15} \mathrm{H}_{8} \mathrm{O}_{7}\left(\mathrm{CH}_{3}\right)_{4}$. The tetramethyl-distylin has evidently one more hydroxyl group, because the tetramethylmonoacetyldistylin, m.p. $186^{\circ} \mathrm{C} \cdot$ was obtained in prismatic crystals through the acetylation of the tetramethyl-distylin with pyridine and acetic anhydride.

In the methanol solution it was indifferent to ferric chloride and positive to the $\mathrm{Mg}-\mathrm{HCl}$ reaction.

From the results, of the above described experiments, it is evident that distylin has five hydroxyl groups in the molecule, four of them belong to the phenolic group and the last to the alcohlic group.

On the acetylation with acetic anhydride and sodium acetate the reaction product was a purple reddish substance which could not be crystallized from any other solvents. On the same treatment the flavanone homolog is generally converted into crystalline chalkone derivative through the cleavage of pyrone linkage. ${ }^{58}$ ) On the other hand, the similar experimental observations with one on distylin were found in the reports of the other natural flavononol 
pigments; ampeloptin and katuranin., ${ }^{735}$ So it was suggested that the same constitutional relationship may exist between distylin and flavanonol compounds. The author could not obtain the oxime derivative through the usual method of oxime-preparation. However it is evident in the literature that on the flavanone compound the carbonyl group in pyrone linkage is active to the usual carbonyl reagents and gives oxime or semicarbazone, ${ }^{59}$ but the flavanonol pigment is generally inactive to the carbonyl reagents under the usual condition.

So distylin can not be considered as one of the flavanone group from this point.

\section{Experimental}

Pentaacetyl-distylin :

1) Distylin ( $0.2 \mathrm{~g})$ was dissolved in pyridine $(10$ c.c. $)$ and mixed with acetic anhydride being cooled all the while with flowing water. After standing for two days, the solution took on a brownish red coloration. The solution was poured with gentle stirring into a large volume of ice water. On further rubbing, the precipitated gummy substance soon became a white solid matter. It was filtered and washed with a little methanol. The insoluble substance in methanol was recrystallized by acetone and then not methanol. The acetyl product was colourless small needles, m.p. $153^{\circ} \mathrm{C}$. The methanolic solution gives light pink coloration to the $\mathrm{Mg}-\mathrm{HCl}$ reaction but the alcoholic solution gives none. It does not develop any coloration to the ferric chloride solution.

\begin{tabular}{lccrc} 
Subst. & $\mathrm{CO}_{2}$ & $\mathrm{H}_{2} \mathrm{O}$ & $\mathrm{C} \%$ & $\mathrm{H} \%$ \\
$22.8 \mathrm{mg}$ & $48.9 \mathrm{mg}$ & $8.6 \mathrm{mg}$ & 58.53 & 4.19 \\
\multicolumn{2}{r}{ Calc. for $\mathrm{C}_{15} \mathrm{H}_{7} \mathrm{O}_{7}\left(\mathrm{COCH}_{3}\right)_{5}$} & 58.36 & 4.28
\end{tabular}

2) Distylin $(0.1 \mathrm{~g})$ was digested with acetic anhydride (5 c.c.), to which was added a drop of conc. sulphuric acid under cooling. Floating substances became instantly deep red and soon dissolved in a yellowish solution. Holding the mixture at room temperature for several hours, and pouring it into ice-water, a solidified mass was separated. It was washed with a large volume of water and purified by redissolving in methanol. It melted at $153^{\circ} \mathrm{C}$ and no depression on the mixed melting point determination 
with the preceding known pentaacetyl-distylin, m.p. $153^{\circ} \mathrm{C}$.

Hydro-lysis of pentaacetyl-distylin (Regeneration of distylin):

At first the author attempted to saponify the product with alcoholic kali, but it was unsuccessful. After that it was effectively taken up to hydrolysis with alcoholic acid as follows: pentaacetyldistylin $(0.3 \mathrm{~g})$ was added to $3 \%$ alcoholic sulphuric acid and boiled in the water bath. In process of time it became yellowish, after 3 hours taken down and cooled on the table. An equal volume of water was poured in it and the mixture was extracted with ether, the ether extract was dried with anhydrous sodium sulphate and evaporated to dryness. The residue was purified from hot water with charcoal. The product was obtained in the same two crystalline forms, long needles and plates, with that of original distylin. It melted at $23 \mathrm{i}^{\circ} \mathrm{C}$ under decomposition.

Pentabenzoyl-distylin:

$0.5 \mathrm{~g}$ of distylin in 3 c.c. of pyridine was gradually mixed with 3 c.c. of benzoylchloride under proper cooling. After two days the mixture was poured in to a large volume of cold water, it gave an reddish oily mass on the bottom. It was washed several times with dilute sulphuric acid to eliminate pyridine and a moderate quantity of alcohol was added with strong stirring. An insoluble part in alcohol was purified from acetone-water and then in acetonc-alcohol mixture. The yield was weighed $0.8 \mathrm{~g}$. It was colourless needles, m.p. $200^{\circ} \mathrm{C}$. It gave a light red coloration in the solution of a large quantity of alcohol, to the $\mathrm{Mg}-\mathrm{HCl}$ reaction and was inactive to the ferric chloride solution.

\begin{tabular}{lcccc} 
Subst. & $\mathrm{CO}_{2}$ & $\mathrm{H}_{2} \mathrm{O}$ & $\mathrm{C} \%$ & $\mathrm{H} \%$ \\
$17.2 \mathrm{mg}$ & $45.7 \mathrm{mg}$ & $6.6 \mathrm{mg}$ & 72.51 & 4.27 \\
& \multicolumn{2}{c}{ Calc. for $\mathrm{C}_{15} \mathrm{H}_{7} \mathrm{O}_{7}\left(\mathrm{COC}_{6} \mathrm{H}_{5}\right)_{5}$} & 72.81 & 3.88
\end{tabular}

Measurement of the molecular weight was executed by the Rast's camphor method.

\begin{tabular}{lrrr} 
Subst. & Camphor & & $\Delta t$ \\
$2.08 \mathrm{mg}$ & $17.01 \mathrm{mg}$ & & 6.0 \\
& Found . & M.W : & 823 \\
\multicolumn{2}{c}{ Calc. for $\mathrm{C}_{15} \mathrm{H}_{7} \mathrm{O}_{7}\left(\mathrm{COC}_{6} \mathrm{H}_{4}\right)_{6}$} & & 824
\end{tabular}

Another benzoylation by the same method produced only the original pentabenzoyl-distylin, m.p. $200^{\circ} \mathrm{C}$.

Tetrabenzoyl-distylin : 
With the insufficient benzoylation, the author obtained colourless needles, m.p. $192^{\circ} \mathrm{C}$. It gave also no coloration to ferric chloride in the alcoholic solution. It was assumed to be tetrabenzoyl-distylin from its analytical figures.

\begin{tabular}{|c|c|c|c|c|}
\hline Subst. & $\mathrm{CO}_{2}$ & $\mathrm{H}_{2} \mathrm{O}$ & $\mathrm{C} \%$ & H \% \\
\hline $18.5 \mathrm{mg}$ & $48.3 \mathrm{mg}$ & $6.7 \mathrm{mg}$ & 71.25 & 4.02 \\
\hline & for $\mathrm{C}_{15} \mathrm{H}_{8}$ & $\left.\mathrm{COC}_{n} \mathrm{H}_{5}\right)_{4}$ & 71.68 & 3.88 \\
\hline
\end{tabular}

Tetramethyl-distylin :

1) Methylation with methyl iodide: Distylin $(0.5 \mathrm{~g})$ was dissolved in acetone $(20$ c.c.) and then methyliodide $(1.5$ c.c.) and potassium carbonate $(2 \mathrm{~g})$ was added to the solution. The mixture was boiled in a water bath, and it gradually became fresh yellow. After 7 hours 1 c.c. of methyliodide was supplemented. Further it was reacted for 5 hours, filtered after cooling and the filtrate gave an oily mass on evaporation of acetone and unchanged methyliodide. The yellowish mass was recrystallized from methanol with charcoal. It gave colourless needles, m.p. $170^{\circ} \mathrm{C}$. The methanolic solution gave no coloration to ferric chloride and developed a light coloration to the $\mathrm{Mg} \cdot \mathrm{HCl}$ reaction.

\begin{tabular}{lcccc} 
Subst. & $\mathrm{CO}_{2}$ & $\mathrm{H}_{2} \mathrm{O}$ & $\mathrm{C} \%$ & $\mathrm{H} \%$ \\
$17.2 \mathrm{mg}$ & $39.9 \mathrm{mg}$ & $8.4 \mathrm{mg}$ & 63.31 & 5.42 \\
\multicolumn{2}{r}{ Calc. for $\mathrm{C}_{15} \mathrm{H}_{8} \mathrm{O}_{7}\left(\mathrm{CH}_{3}\right)_{4}$} & 63.33 & 5.55
\end{tabular}

Measurement of methoxyl group;

$\begin{array}{lcc}\text { Subst. } & \mathrm{AgI} & \mathrm{OCH}_{3} \% \\ 10.4 \mathrm{mg} & 26.8 \mathrm{mg} & 34.31 \\ & \text { Calc. for } \mathrm{C}_{15} \mathrm{H}_{8} \mathrm{O}_{7}\left(\mathrm{CH}_{3}\right)_{4} & 34.40\end{array}$

2) Methylation with dimethylsulphate: Distylin $(0.5 \mathrm{~g})$ was mixed with dimethylsulphate $(3$ c.c.) and then in the course of two days at room temperature $30 \%$ potassium hydroxide was introduced very gradually drop by drop with stirring. During the addition of the reagent the solution was kept faintly alkaline throughout with strict attention. The product was filtered, but, inspite of evasion from strong alkaline reaction, it appeared a reddish resin-like mass. On several purifications from methanol it gave colourless needles, m.p. $170^{\circ} \mathrm{C}$ in very small yeild, which was determined as tetramethyl-distylin through the mixed melting point determination.

3) Methylation with diazomethane: Nitrosomethylurea was prepared from potassium cyanate and methylamine hydroch- 
loride $^{\text {(n) }}$ and utilized as the following methylation ragent. $1.3 \mathrm{~g}$ of distylin was suspended in 20 c.c. of ether and, on addition of ether solution of diazomethane which generated from $3 \mathrm{~g}$ of nitrosomethylurea, it severely reacted under bubbling of nitrogen gas. To dissolve the still unchanged substance, it was supplemented with more ether solution of diazomethane, which was prepared from $3 \mathrm{~g}$ of nitrosomethylurea. After standing over night, with fixation of calcium-tube, the ether solution was evaporated and the residue was treated with a small quantity of methanol. The insoluble portion in methanol was recrystallized from hot methanol with addition of water. It yielded the same methyl derivative, m.p. $170^{\circ} \mathrm{C}$. In the soluble part in methanol, the author found one more colourless needle, m.p. $128^{\circ} \mathrm{C}$. This product developed a brownish coloration to ferric chloride and also was active to the $\mathrm{Mg} \cdot \mathrm{HCl}$ reaction. It is assumed to be trimethyl-distylin, but the author could not determine this point from the analytical figures, because it was only obtained in a very small quantity.

Tetramethyl monoacetyl-distylin :

Tetramethyl-distylin $(0.13 \mathrm{~g})$ was dissolved in warm pyridine ( 2 c.c.) and acetic anhydride ( 2 c.c.) was added to it. After standing for two days, it was poured into a large quantity of ice-water, and the separated crystalline mass was filtered. It was purified from methanol in short prismatic crystals. It melted at $180^{\circ} \mathrm{C}$. The methanolic solution gave no coloration with ferric chloride and was positive to the $\mathrm{Mg} \cdot \mathrm{HCl}$ reaction.

$\begin{array}{llcrl}\text { Subst. } & \mathrm{CO}_{2} & \mathrm{H}_{2} \mathrm{O} & \mathrm{C} \% & \mathrm{H} \% \\ 19.3 \mathrm{mg} & 43.9 \mathrm{mg} & 9.0 \mathrm{mg} & 62.07 & 5.18 \\ & \text { Calc. for } \mathrm{C}_{15} \mathrm{H}_{7} \mathrm{O}_{7}\left(\mathrm{CH}_{3}\right)_{4}\left(\mathrm{COOH}_{3}\right) & 62.68 & 5.47\end{array}$

Action of the carbonyl reagent:

Distylin $(0.1 \mathrm{~g})$ in alcohol was mixed with an aqueous solution, in which hydroxylamine hydrochloride $(0.1 \mathrm{~g})$ and anhydrous sodium acetate $(0.15 \mathrm{~g})$ were dissolved in two drops of water, and boiled on water bath for five hours. The mixture was liberated from alcohol and poured in ice-water. The separated white crystalline mass gave an original distylin, m.p. $230^{\circ} \mathrm{C}$, which does not contain nitrogen atom. 